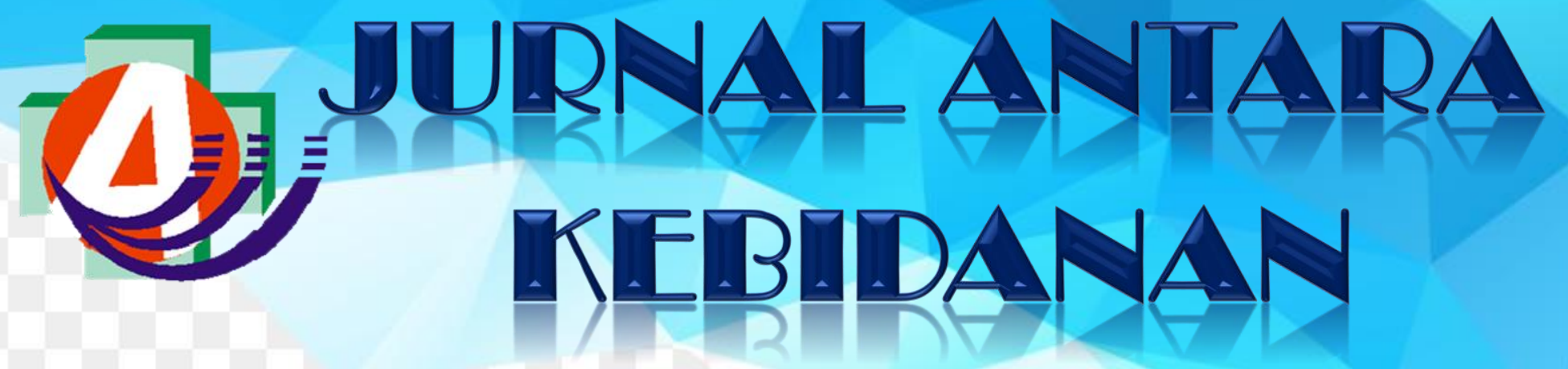

1. Faktor-Faktor Yang Berhubungan Dengan Kematian Bayi Berat Lahir Rendah Di RSUD Labuang Baji Makassar (Daswati, Nurbiah Eka Susanty)

2. Hubungan Dukungan Suami Dan Usia Ibu Hamil Dengan Kunjungan Antenatal Careldeal Di Puskesmas Mamboro Palu (Erni)

3. Dampak Berat Badan Lahir Rendah Terhadap Kehamilan Yang Tidak Diinginkan (Feva Tridiyawati, Mariyani, Resi Galaupa)

4. Pengetahuan Remaja Tentang Infeksi Menular Seksuak Di SMK Jaya Cimuning Bekasi Tahun 2020

(Tuty Yanuarti,Novita, Lia Idealistiana)

5. Keterlibatan Orangtua Terhadap Pendidikan Anak Usia Dini (Mariyani, Ita Herawati, Rahayu Khairiah)

6. Pengaruh Ibu Hamil Trimester I Dalam Upaya Penanganan Mual Muntah (Rahayu Khairiah,Feva Tridiyawati, Tuty Yanuarti)

7. Pengaruh Responsiveness Dan Assurance Perawat Terhadap Kepuasan Pasien Di Ruang Instalasi Gawat Darurat RSU UKI (Maryati Sutarno, Natalina Panjaitan)

8. Hubungan Pengetahuan Ibu Tentang Imunisasi Booster Dengan Imunisasi Dasar Lengkap Di Wilayah Kerja Puskesmas Bojong Rawa Lumbu (Nur Sitiyaroh, Siarny Dormy Manalu, Nurlaela)

9. Faktor-Faktor Yang Berhubungan Dengan Perilaku Higienis Saat Menstruasi (Lucy Amelia, Nadra Sylvia F)

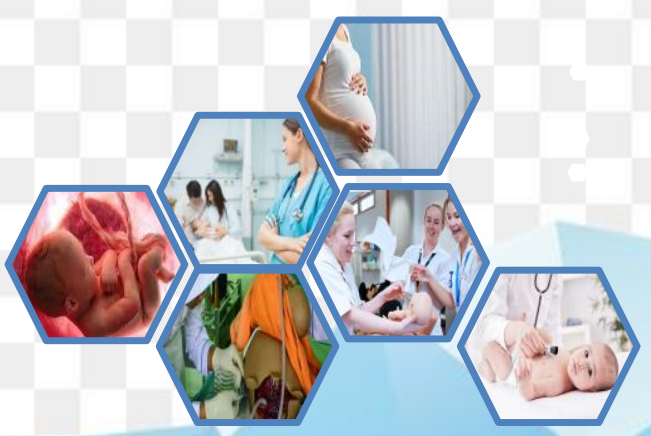

Volume 4 Nomer 1 


\title{
Hubungan Dukungan Suami dan Usia Ibu Hamil dengan Kunjungan Antenatal Care Ideal di Puskesmas Mamboro Palu
}

\author{
Erni \\ Akademi Kebidanan Graha Ananda Palu \\ E-mail : erniarnia@yahoo.co.id
}

\begin{abstract}
ABSTRAK
Tujuan dari penelitian ini adalah untuk mencari hubungan dukungan suami dan usiaibu hamil dengan kunjungan antenatal care ideal di Puskesmas Mamboro Palu Tahun 2018. Jenis penelitian ini adalah Cross Sectional Study dimana penelitian ini merupakan desain penelitian dengan melakukan observasi dan tekhnik pengambilan sampel menggunakan purposive sampling, dengan jumlah sampel $30 \mathrm{ibu}$ hamil trimester III. Analisa data yangdigunakan yaitu analisa univariat, dan analisa bivariat, pengumpulan data dengan lembar observasi. Data diolah menggunakan uji statistic uji chi-square hubungan dukungan suamidengan kunjungan antenatal care ideal diperoleh nilai $\rho=0,000$ lebih kecil dari $\alpha=0,05$ maka $\rho<\alpha$ berarti hipotesisnya Ha diterima dan Ho ditolak. Dengan demikian ada hubungandukungan suami dengan kunjungan antenatal care ideal. Hubungan dukungan usia ibu hamildengan kunjungan antenatal care ideal diperoleh nilai $\rho=0,006$ lebih kecil dari $\alpha=0,05$ maka $\rho<\alpha$ berarti hipotesisnya Ha diterima dan Ho ditolak. Dengan demikian ada hubungan usiaibu hamil dengan kunjungan antenatal care ideal.
\end{abstract}

Kata Kunci : Dukungan Suami, Usia Ibu hamil, Kunjungan Antenatal Care IdealDaftar

\section{ABSTRACT}

The purpose of this study was to find the relationship between husband's support and the ageof pregnant women with an ideal antenatal care visit at Palu Mamboro Health Center in 2018. This type of research is Cross Sectional Study where this research is a research designby observing and sampling techniques using purposive sampling, with a sample of 30pregnant women in the third trimester. Data analysis used is univariate analysis, andbivariate analysis, data collection with observation sheets. The data were processed using statistical tests of chi-square test, the relationship between husband's support and the ideal antenatal care visit was obtained by the value of $\rho=0,000$ smaller than $\alpha=0.05$, so $\rho<\alpha$ means that the hypothesis Ha is accepted and Ho is rejected. Thus there is a relationship between husband's support and the ideal antenatal care visit. The relationship between the age support of pregnant women and the ideal antenatal care visit obtained a value of $\rho=0.006$ smaller than $\alpha=0.05$ so that $\rho<\alpha$ means that the hypothesis Ha is accepted and Ho is rejected. Thus there is an age relationship between pregnant women and ideal antenatalcare visits.

Key Word : Husband Support, Age of Pregnant Women, Ideal Antenatal Care Visit

\section{PENDAHULUAN}

Kunjungan antenatal care (ANC) yaitu kontak ibu hamil dengan pemberian perawatan/asuhan dalam hal mengkajian kesehatan dan keselahteraan bayi, serta kesempatan untuk memperoleh informasi dan memberikan informasi bagi ibu dan petugas kesehatan (Sri Astuti,dkk. 2016).

Berdasarkan hasil penelitian Belliana Dwi Wahyu dkk tentang Hubungan tingkat pengetahuan, umur dan paritas ibu hamil dengan kesadaran melakukan $\mathrm{K} 4$ di
Puskesmas Bandarharjo semarang tahun 2014. Responden yang tidak melakukan kunjungan K4 sesuai standar diperoleh proporsi terbesar dari responden yang berusia reproduksi tidak sehat, yaitu dengan persentase sebesar $62,5 \%$, namun terdapat juga responden dengan usia reproduksi sehat yang tidak melakukan kunjungan K4 yaitu sebesar $24,5 \%$. Dari 5 responden yang tidak melakukan $\mathrm{K} 4$ pada usia reproduksi tidak sehat terdiri dari 2 responden berusia $<20$ tahun dan 3 
responden berusia >35 tahun. Dari hasil analisis dengan uji korelasi Spearman, didapatkan $\mathrm{p}$ value 0,029 pada derajat kemaknaan $5 \%$ yang artinya terdapat hubungan variabel independen dengan variabel dependen. Hal ini menunjukkan ada hubungan yang bermakna antara umur ibu dengan kesadaran melakukan K4.

Dukungan suami mempunyai andil besar dalam status. Berdasarkan survey awal yang peneliti lakukan di Puskesmas Mamboro Palu, didapatkan jumlah ibu hamil pada tahun 2016 yaitu 2.887 orang, yang terdiri dari Trimester I/K1 sebesar 1.100 orang $(38,1 \%)$, Trimester II/K2 sebesar 832 orang $(28,8 \%)$, Trimester III/K3 sebesar 715 orang $(24,7 \%)$ dan ibu hamil yang melakukan K4 sebesar 470 orang (16,2\%). Pada tahun 2017 mengalami penurunan jumlah ibu hamil yaitu 2.667 orang, yang terdiri dari Trimester I/K1 sebesar 870 orang (32,6\%), Trimester II/K2 sebesar 750 orang $(28,1 \%)$, Trimester III/K3 sebesar 547 orang $(20,5 \%)$ dan ibu hamil yang melakukan K4 sebesar 500 orang $(18,7 \%)$. Wawancara yang dilakukan kepada petugas kesehatan di ruangan Poliklinik Kesehatan Ibu dan Anak (KIA) diketahui bahwa rata-rata Ibu hamil yang berusia 2030 tahun datang diantar oleh suami saat melakukan kunjungan antenatal care dan merasa senang karena suami mendukung kehamilannya.

Antenatal care atau pemeriksaan kehamilan merupakan pemeriksaan ibu hamil baik fisik dan mental serta menyelamatkan ibu dan anak dalam kehamilan, persalinan dan masa nifas, sehingga keadaan mereka post partum sehat dan normal (Padila, 2014). Hasil penelitian di Indonesia mengatakan bahwa dukungansuami yang diharapkan istri yaitu suami sangat mendambakan bayi dalam kandungan istri, suami senang mendapat keturunan, suami menunjukkan kebahagiaan pada kehamilan ini, suami memperhatikan kesehatan istri yakni menanyakan keadaan istri dan janin yang ada dalam kandungan, suami tidak menyakiti istri, suami dapat menghibur dan menenangkan istri ketika ada masalah yang di hadapi istri, suamimenasehati istri agar istri tidak terlalu capek bekerja, suami membantu tugas istri, suami berdoa untuk kesehatan istrinya dan janin dalam kandungan, suami menunggu istri saat melahirkan maupun ketika istri harus di operasi (Rukiyah, 2014).

\section{METODE PENELITIAN}

\section{Jenis Penelitian}

Jenis penelitian yang di gunakan adalah penelitian Survey Analitik dengan menggunakan desain "Cross Sectional" dimana penelitian ini merupakan suatu rancangan penelitian observasi yang dilakukan untuk mengetahui hubungan variable independent dengan variabel dependen dimana pengukurannya dilakukan pada suatu waktu atau dalam periode waktu yang pendek ( $\mathrm{H}$. Syamsunie Carsel HR, 2017), sehingga peneliti dapat mengetahui informasi mengenai Hubungan Dukungan Suami dan Usia Ibu hamil dengan Kunjungan Antenatal Care Ideal di Puskesmas Mamboro Palu tahun 2018.

\section{Lokasi dan Waktu Penelitian}

Penelitian ini dilaksanakan di Puskesmas Mamboro Palu pada tahun 2018. Penelitian ini dilaksanakan pada bulan Maret - Juni 2018.

\section{Populasi dan Sampel}

Populasi dalam penelitian ini adalah Semua Ibu hamil yang melakukan 
pemeriksaan Antenatal Care bulan aprilmei 2018 sebanyak 156 orang. Sampel dalam penelitian ini adalah sebagian ibu hamil trimester III yang melakukan pemeriksaan Antenatal Care di Puskesmas Mamboro.

\section{HASIL PENELITIAN}

Tabel 1

Distribusi Frekuensi Tentang Kunjungan Antenatal Care Ideal Di Puskesmas Mamboro Palu tahun 2018

\begin{tabular}{l|c|c}
\hline $\begin{array}{c}\text { Kunjungan Antenatal } \\
\text { Care Ideal }\end{array}$ & Frekuensi & Presentase (\%) \\
\hline Anc Ideal & 18 & $\mathbf{6 0 , 0}$ \\
\hline Kurang Ideal & 12 & $\mathbf{4 0 , 0}$ \\
\hline Jumlah & $\mathbf{3 0}$ & $\mathbf{1 0 0}$ \\
\hline
\end{tabular}

Sumber : Data Primer 2018

Berdasarkan tabel 1 menunjukkan bahwa dari 30 responden, jumlah ibu hamil yang melakukan kunjungan antenatal care ideal sebanyak 18 orang $(60,0 \%)$ dan ibu hamil yang melakukan kunjungan antenatal care kurang ideal sebanyak 12 orang $(40,0 \%)$.

Tabel 2

Hubungan Dukungan Suami denganKunjungan Antenatal Care Ideal Di Puskesmas Mamboro Palu Tahun 2018

\begin{tabular}{|c|c|c|c|c|c|c|c|}
\hline \multirow{3}{*}{$\begin{array}{c}\text { Dukungan } \\
\text { Suami }\end{array}$} & \multicolumn{4}{|c|}{ Kunjungan ANC } & \multirow{2}{*}{\multicolumn{2}{|c|}{ Jumlah }} & Nilai $\rho$ \\
\hline & \multicolumn{2}{|c|}{ ANC Ideal } & \multicolumn{2}{|c|}{$\begin{array}{l}\text { ANC Kurang } \\
\text { Ideal }\end{array}$} & & & \multirow{5}{*}{$\rho=0,000$} \\
\hline & $\mathrm{N}$ & $\%$ & $\mathrm{~N}$ & $\%$ & $\mathrm{~N}$ & $\%$ & \\
\hline Didukung & 15 & 50,0 & 1 & 3,3 & 16 & 53,3 & \\
\hline Kurang didukung & 3 & 10,0 & 11 & 36,7 & 14 & 46,7 & \\
\hline Jumlah & 18 & 60,0 & 12 & 40,0 & 30 & 100 & \\
\hline
\end{tabular}

Sumber : Data Primer 2018

Tabel 2 menunjukkan bahwa dari 30 responden, jumlah ibu hamil yang mendapat dukungan suami dengan kunjunganantenatal care sebanyak 16 orang $(53,3 \%)$, terdiri dari 15 orang $(50 \%)$ ibu hamil yang melakukan kunjungan anc ideal dan 1 orang $(3,3 \%)$ ibu hamil yang melakukan kunjungan antenatal care kurang ideal. Jumlah ibu hamil yang kurang mendapat dukungan suami dengan kunjungan antenatal care sebanyak 14 orang $(46,7 \%)$, terdiri dari 3 orang $(10 \%)$ ibu hamil yang melakukan kunjungan antenatal care ideal dan 11 orang $(36,7 \%)$ ibu hamil yang melakukan kunjungan antenatal care kurang ideal.

Tabel 3

Hubungan Usia Ibu Hamil dengan Kunjungan Antenatal Care Ideal

Di Puskesmas Mamboro Palu Tahun 2018 


\begin{tabular}{|c|c|c|c|c|c|c|c|}
\hline \multirow{3}{*}{ Usia Ibu Hamil } & \multicolumn{4}{|c|}{ Kunjungan ANC } & \multirow{2}{*}{\multicolumn{2}{|c|}{ Jumlah }} & Nilai $\rho$ \\
\hline & \multicolumn{2}{|c|}{ ANC Ideal } & \multicolumn{2}{|c|}{ ANC Kurang Ideal } & & & \multirow{5}{*}{$\rho=0,006$} \\
\hline & $\mathrm{N}$ & $\%$ & $\mathrm{~N}$ & $\%$ & $\mathrm{~N}$ & $\%$ & \\
\hline Resiko Tinggi & 6 & 20,0 & 9 & 30,0 & 15 & 50,0 & \\
\hline Resiko Rendah & 12 & 40,0 & 3 & 10,0 & 15 & 50,0 & \\
\hline Jumlah & 18 & 60,0 & 12 & $\mathbf{4 0 , 0}$ & 30 & 100 & \\
\hline
\end{tabular}

Sumber : Data Primer 2018

Tabel 4.8 menunjukkan bahwa dari 30 responden, jumlahibu hamil usia resiko tinggi dengankunjungan antenatal antenatal care sebanyak 15 orang $(50,0 \%)$, terdiri dari 6 orang (20\%) ibu hamil yang melakukan kunjungan anc ideal dan 9

\section{PEMBAHASAN}

\section{Karakteristik Responden}

Berdasarkan hasil pengelolahan data menunjukkan bahwa sebagian besar ibu tidak bekerja yang datang melakukan pemeriksaan kehamilan, Ibu yang tidak bekerja mempunyai waktu yang lebih fleksibel untuk mengurus anak dan keluarganya. Sebagian besar waktu ibu digunakan untuk melaksanakan tugas rumah tangga sehingga waktunya tidak terikat pada jam kerja tertentu. Waktu yang fleksibel memungkinkan bagi ibu untuk melakukan aktifitas lain termaksuk untuk mempehatikan dan mempersiapkan kehamilannya dengan lebih baik. Pada ibu yang bekerja kemungkinan tidak memiliki waktu untuk perawatan kehamilan dengan melakukan kunjungan anc.

Berdasarkan hasil pengelolahan data menunjukkan bahwa sebagian ibu berpendidikan menengah yang melakukan kunjungan anc ideal, tingkat pendidikan menunjukkan jenjang pendidikan formal yang telah ditempuh ibu hamil. Pendidikan menengah dalam (40\%) yang melakukan kunjungan anc ideal dan 3 orang (10\%) ibu hamil yang melakukan kunjungan anc kurang ideal. orang $(30 \%)$ ibu hamil yang melakukan kunjungan anc kurang ideal. Jumlah ibu hamil usia resiko rendah dengan kunjungan antenatal care sebanyak 15 orang $(50 \%)$, terdiri dari 12 orang ibu hamil.

Berdasarkan hasil analisis Chisquare diperoleh nilai $\rho=0,006$ lebih kecil dari $\alpha=0,05$, ini berarti Ho ditolak dan $\mathrm{Ha}$ diterima maka ada hubungan usia ibu hamil dengan kunjungan antenatal care ideal.

Notoatmodjo (2010) menyatakan bahwa semakin tinggipendidikan seseorang maka akansemakin mudah dalam menerima informasi dan semakin baik pengetahuan yang dimiliki sehingga mempengaruhi perilaku seseorang, termaksuk kepatuhan ibu hamil dalammelakukan kunjungan anc. Pendidikan yang dimiliki ibu berhubungan dengan banyaknya pengetahuan dan luasnya wawasan yang dimiliki oleh ibu. Ibu dengan pendidikan menengah diartikan telah mempunyai kemampuan menyerap berbagai informasi informasi yang masuk kepadanya.

Berdasarkan hasil pengelolahan data menunjukkan bahwa sebagian ibu multipara, dimana ibu yang sudah pernah melahirkan sudah mengetahui manfaat dari pemeriksaan anc, informasi yang diperoleh dari tenaga kesehatan sehingga rutin melakukan pemeriksaan kehamilan dan ibu yang belum pernah atau baru pertama kali mengalami kehamilan malas melakukan pemeriksaan kehamilan karena belum 
mengetahui resiko dan komplikasi yang akan terjadi. Berdasarkan hasil pengelolahan data menunjukkan bahwa sebagian ibu hamil yang melakukan kunjungan antenatal care ideal, ibu yang melakukan antenatal care dapat memperoleh keuntungan-keuntunganseperti dapat mendeteksi dini terhadap komplikasi ibu dan janin.

\section{Hubungan Dukungan Suami dengan Kunjungan Antenatal Care Ideal}

Dukungan suami adalah dukungan yang diberikan suami kepada istri, suatu bentuk dukungan dimana suami dapat memberikan bantuan secara psikologis baik berupa motivasi, perhatian dan penerimaan. Suami mempunyai suatu tanggung jawab yang penuh dalam suatu keluarga tersebut dan mempunyai peranan yang sangat penting yaitu dituntut bukan hanya sebagai pencari nafkah, tetapi juga sebagai motivator dalam berbagai kebijakan yang akan diputuskan termaksuk merencanakan keluarga. Dukungan dan partisipasi suami sangat dibutuhkan oleh seorang isteri pada saat hamil, antara lain suami harus dapat menghindari 3T yaitu : terlambat mengambil keputusan, terlambat ke tempat pelayanan kesehatan dan terlambat memperoleh pelayanan medis. Seorang suami hendaknya waspada dan berjaga-jaga serta bertindak jika melihat adanya tandatanda bahaya dalam kehamilan.

Salah satu faktor yang mempengaruhi keteraturan ibu melakukan kunjungan anc yaitu pengetahuan suami tentang pentingnya pemeriksaan Antenatal Care dan mudahnya akses informasi yang diterima oleh suami mengenai kunjungan antenatal yang ideal dilakukan serta keinginan suami untuk meningkatkan derajat kesehatan keluarga. Mendukung isteri selama kehamilan hingga melahirkan merupakan hak dan sekaligus kewajiban seorang suami. Oleh karena itu sejalan dengan hasil penelitian yang diperoleh menunjukkan bahwa ibu yang melakukan kunjungan antenatal care ideal mendapat dukungan suami lebih banyak dari ibu yang melakukan kunjungan antenatal care kurang ideal. Fakta ini sesuai dengan teori yang dikemukakan oleh Kusmiyati dkk (2009) bahwa orang yang paling penting bagi seorang wanita hamil biasanya ialah ayah sang anak. Semakin banyak bukti menunjukkan bahwa wanita yang diperhatikan dan dikasihi oleh pasangannya selama hamil akan menunjukkan lebih sedikit gejala emosi dan fisik, lebih sedikit komplikasi persalinan, dan lebih mudah melakukan penyesuaian selama masa nifas.

Dari 30 responden, jumlah ibu hamil yang mendapat dukungan suami dengan kunjungan antenatal care sebanyak 16 orang $(50,0 \%)$, terdiri dari 15 orang (50\%) ibu hamil yang melakukan kunjungan anc ideal dan 1 orang ( $3,3 \%)$ ibu hamil yang melakukan kunjungan anc kurang ideal. Jumlah ibu hamil yang kurang mendapat dukungan suami dengan kunjungan antenatal care sebanyak 14orang $(46,7 \%)$, terdiri dari 3 orang $(10 \%)$ ibu hamil yang melakukan kunjungan antenatal care ideal dan 11 orang (36,7\%) ibu hamil yang melakukan kunjungan anc kurang ideal.

Berdasarkan hasil analisis Chisquare diperoleh nilai $\rho=0,000$ lebih kecil dari $\alpha=0,05$, ini berarti Ho ditolak dan $\mathrm{Ha}$ diterima ada hubungan dukungan suami dengan kunjungan antenatal care ideal. Dukungan suami menjadi salah satu unsur terpenting dalam membantu ibu menyelesaikan masalah. Apabila ada dukungan, maka rasa percaya diri akan bertambah dan motivasi ibu untuk melakukan pemeriksaan kehamilan akan 
meningkat. Walaupun suami melakukan hal kecil, tindakan tersebut mempunyai makna yang berarti dalam meningkatkan kesehatan psikologis ibu hamil kearah yang lebih baik.

Hasil penelitian ini, sejalan dengan yang dilakukan oleh Muliaty arif (2016) di RSUD Syekh Yusuf Gowa bahwa jumlah ibu hamil yang mendapatkan dukungan suami kurang dengan kunjungan ANC kurang sebanyak 7 orang $(8,0 \%)$, dukungan suami kurang dengan kunjungan ANC lengkap sebanyak 18 orang (20,5\%), dukungan suami baik dengan kunjungan ANC kurang sebanyak 5 orang $(5,7 \%)$ dan dukungan suaami baik dengan kunjungan ANC lengkap sebanyak 58 orang $(65,9 \%)$, ada hubungan dukungan suami dengan pelayanan ANC dimana nilai $\rho=0,013$ lebih kecil dari $\alpha=0,05$ yang berarti Ho ditolak dan Ha diterima.

Hasil Penelitian sejalan dengan yang dilakukan Nurul Aryastuti tentang hubungan dukungan suami dengan kelengkapan melakukan kunjungan ANC pada ibu hami TM III di Puskesmas Jetis II Bantul tahun 2013, menunjukkan bahwa sebagian besar yaitu 26 orang atau $81,25 \%$, ibu hamil trimester III mendapatkan dukungansuami yang baik, 4 orang atau $12,5 \%$ mendapat dukungan cukup dan 2 orang mendapat dukungan suami kurang. Sebagian besar yaitu 29 orang atau 90,6\% ibu hamil trimester III melakukan kunjungan ANC secara lengkap dan 3 orang atau 9,4\% tidak lengkap. Jadi disimpulkan ada hubungan dukungan suami dengan kelengkapan kunjungan ANC pada ibu hamil trimester III.

Menurut penulis bahwa ibu yang mendapat dukungan suami dapat meningkatkan kepatuhan ibu hamil melakukan kunjungan antenatal care, karena peran suami dapat memberikan dukungan emosional, perhatian, motivasi dan informasi pada masa kehamilan ibu.

\section{Hubungan Usia Ibu hamil dengan Kunjungan Antenatal Care Ideal}

Umur sangat menentukan suatu kesehatan ibu, dikatakan berisiko tinggi apabila ibu hamil berusia di bawah 20 tahun dan di atas 35 tahun. Umur dibawah 20 tahun dikhawatirkan mempunyai risiko komplikasi yang erat kaitannya dengan kesehatan reproduksi wanita, diatas 35 tahun mempunyai risiko tinggi karena adanya kemunduran fungsi alat reproduksi. Gangguan ini bukan hanya bersifat fisik karena belum optimalnya perkembangan fungsi organ- organ reproduksi, namun secara psikologis belum siap menanggung beban moral, mental, dan gejolak emosional yang timbul serta kurang pengalaman dalam melakukan pemeriksaan ANC. Usia aman untuk kehamilan dan persalinan adalah 20-30 tahun.

Usia merupakan factor predisposisi seseorang untuk memutuskan memanfaatkan pelayanan kesehatan karena usia mempengaruhi daya tangkap seseorang, semakin bertambahnya usia semakinberkembang pula daya tangkap dan pola pikirnya sehingga pengetahuan yang diperoleh semakin membaik. Semakin bertambah usia ibu, akan mengalami kecenderungan untuk melakukan hal yang postif dalam upaya menjaga kesehatan janinnya saat masakehamilan.

Kriteria ibu yang aman melahirkan 20-35 tergolong dalam usia produktif, ibu dengan usia > 35 tahun akan merasa malu dan kurang percaya melakukan pemeriksaan kehamilan. Pola berfikir masyarakat seharusnya pada upaya promotif dimana melakukan pencegahan dengan memperhatikan upaya awal dengan 
memelihara kesehatan dalam hal ini kehamilannya dengan cara sadar akan pentingnya pemeriksaan antenatal yang teratur sehingga dapat mencegah dan mendeteksi secara dini terjadinya komplikasi dalam kehamilan.

Dari 30 responden, jumlah ibu hamil usia resiko tinggi dengan kunjungan antenatal antenatal care sebanyak 15 orang $(50,0 \%)$, terdiri dari 6 orang $(20,0 \%)$ ibu hamil yang melakukan kunjungan anc ideal dan 9 orang (30\%) ibu hamil yang melakukan kunjungan anc kurang ideal. Jumlah ibu hamil usia resiko rendah dengan kunjungan antenatal care sebanyak 15 orang (50\%), terdiri dari 12 orang ibu hamil (40\%) yang melakukan kunjungan anc ideal dan 3 orang (10\%) ibu hamil yang melakukan kunjungananc kurang ideal.

Berdasarkan hasil analisis Chisquare diperoleh nilai $\rho=0,006$ lebih kecil dari $\alpha=0,05$, ini berarti Ho ditolak dan Ha diterima, ada hubungan usia ibu hamil dengan kunjungan antenatal care ideal. Hasil penelitian ini sejalan dengan penelitian yang dilakukan oleh Shinta dewi kandilo putri dkk (2016) memiliki usia < 20 tahun, yaitu sejumlah 33 orang $(51,6 \%)$, usia 20 - 35 tahun sejumlah $21(32,8 \%)$ dan usia > 35 tahun sejumlah 10 orang (15,6\%). Dari hasil penelitian pada 64 responden ibu hamil, di dapatkan hasil pada TM I sebanyak $3(4,68 \%)$ ibu hamil yang tidak patuh melakukan ANC, TM II sebanyak $9(14,06 \%)$ dan pada TM III sebanyak 26 (40,62\%). Ada hubungan yang signifikan antara usia Ibu hamil terhadap kepatuhan ANC dengan p-value $=0,000<$ $\alpha(0,05$ berarti ada hubungan antara usia ibu hamil terhadap kepatuhan ANC. Sebagin besar berusia kurang dari 20 tahun yaitu 51,6\%. Sedangkan kepatuhan ibu hamil dalam melakukan ANC 59,4\% ada hubungan yang signifikan antara usia Ibu hamil terhadap kepatuhan ANC dengan pvalue $=0,000<\alpha(0,05)$, disimpulkan bahwa ada hubungan yang signifikan antara usia Ibu hamil terhadap kepatuhan ANC di Puskesmas Suruh Kabupaten Semarang. Hasil penelitian ini sejalan dengan penelitian yang dilakukan oleh Belliana Dwi Wahyu dkk (2014). Responden yang tidak melakukan kunjungan K4 sesuai standar diperoleh proporsi terbesar dari responden yang berusia reproduksi tidaksehat, yaitu dengan persentase sebesar $62,5 \%$, namun terdapat juga responden dengan usia reproduksi sehat yang tidak melakukan kunjungan K4 yaitu sebesar 24,5\%. Dari 5 responden yang tidak melakukan K4 pada usia reproduksi tidak sehat terdiri dari 2 responden berusia $<20$ tahun dan 3 responden berusia >35 tahun. Dari hasil analisisdengan uji korelasi Spearman, didapatkan $\mathrm{p}$ value 0,029 pada derajat kemaknaan 5\% yang artinya terdapat hubungan variabel independen dengan variabel dependen. Hal ini menunjukkanada hubungan yang bermakna antara umur ibu dengan kesadaran melakukan K4.

Menurut penulis, usia mempengaruhi pola piker seorang ibu. Ibu dengan usia produktif (20-35 tahun) dapat berpikir lebih rasional dibandingkan dengan ibu usia yanglebih muda atau lebih tua. Sehingga ibu dengan usia produktif memiliki motivasi lebih dalam memeriksakan kehamilannya. Dari motivasi tersebut mempengaruhi sikap ibu hamil dimana sikap yang positif atau respon yang baikdari ibu hamil akan tercermin terhadap kepeduliannya dalam meningkatkan kesehatan diri dan janinnya sehingga dapat meningkatkan keteraturan kunjungan sedangkan sikap yang negative membuat ibu hamil kehilangan motivasinya untuk melakukan kunjungan antenatal care. 
Untuk itu pemahaman mengenai antenatal care harus terlebih dahulu dimiliki. Ibu hamil yang sudah paham dengan kehamilannya secara tidak langsung akan terjadi proses menimbang dalamdirinya.

\section{KESIMPULAN}

Ada hubungan dukungan suami dengan kunjungan antenatal care ideal, hasilyang diperoleh yaitu dari 30 responden ibu hamil trimester III yang melakukan kunjungan antenatal care, sebanyak 16 orang $(53,3 \%)$ ibu hamil yang mendapatkan dukungan suami dan sebanyak 14 orang $(46,7 \%)$ ibu hamil yang kurang mendapat dukungan suami dengan kunjungan antenatal care, dengan nilai $\rho=0,000$ lebih kecil dari nilai $\alpha=0,05$. Ada hubungan usia ibu hamil dengan kunjungan antenatal care ideal dengan hasil yang diperoleh yaitu dari 30 responden ibu hamil trimester III yang melakukan kunjungan antenatal care, sebanyak 15 orang $(50,0 \%)$ ibu hamil usia resiko tinggi dan 15 orang $(50,0 \%)$ ibu hamil usia resiko rendah, dengan nilai $\rho=$ 0,006 lebih kecil dari nilai $\alpha=0,05$.

\section{SARAN}

Bagi petugas kesehatan, agar memberikan Pendidikan Kesehatan tentang pentingnya melakukan kunjungan antenatal care untuk mencengah komplikasi. Memberikan motivasi dan membina hubungan akrab terhadap ibu hamil yang datang melakukan kunjungan antenatal care.

Bagi tempat penelitian, diharapkan hasil penelitian ini dapat menjadi bahan masukan bagi Puskesmas untuk melakukan promosi kesehatan dengan penyuluhan tentang pentingnya dilakukan kunjungan antenatal care untuk mendeteksi dan mencengah terjadinya komplikasi.

\section{DAFTAR PUSTAKA}

Astuti, Maya. 2014. Buku Pintar Kehamilan.Jakarta: EGC

Astuti, Sri, 2016. Asuhan Ibu Hamil dalam Masa Kehamilan: PT. Gelora Aksara Pratama.

Berdasarkan hasil penelitian Belliana Dwi Wahyu dkk tentang Hubungan tingkat pengetahuan, umur dan paritas ibu hamil dengan kesadaran melakukan K4 di Puskesmas Bandarharjo semarangtahun 2014. (Online)

(ejurnal.akbidpantiwilasa.ac.id/index. $\mathrm{ph}$

p/kebidanan/article/download/36/35).

Diambil pada tanggal 2 Februari 2018

Berdasarkan hasil penelitian Rury Narulita Sari dan Eny Pemilu Kusparlina, tentang Hubungan dukungan suami dengan ketepatan Antenatal Care Di

Desa Bagi Kabupaten Madiun tahun 2017. (online).

Carsel, Syamsunie. 2017. Metode Penelitian Kesehatan dan Umum. Madura: Ajrie.

Dinas Kesehatan Provinsi Sulawesi Selatan. Profil Kesehatan Sulawesi Selatan. Palu. 2014

Dwi Maharani, Yupika, 2017. Buku Pintar Kebidanan dan Keperawatan. Yogyakarta: CV Solusi Distribusi

Elizabeth, 2013. Asuhan Kebidanan Kehamilan: IN MEDIA

Fitrihanda. 2012. Antenatal Care. http://digilib.unimus.ac.id/files/disk1/ 113/jtpt unimus-941-fitrihanda-56194.babii.pdf. Diakses 10 Februari 2018

Hasil Penelitian Nurul Aryastuti tentang hubungan dukungan suami dengan kelengkapan melakukan kunjungan ANC pada ibu hamil TM III di Puskesmas Jetis II Bantul tahun 2013

(online) 
(digilib.unisayogya.ac.id/1354/1/nask ah\%20publikasi.pdf. oleh S Sugiyanto - 2013). Diambil pada tanggal 2 Februari 2018

Hasmi. 2016. Metode Penelitian Kesehatan: IN MEDIA

Kementrian Kesehatan. RI. Profil Kesehatan Indonesia. Jakarta; 2015

Kusmiyati, Yuni dan Heni Puji, 2015. Wahyuningsih. Asuhan Ibu Hamil. Yogyakarta: Fitramaya

Notoatmodjo, soekidjo. 2010. Metodelogi

Penelitian Kesehatan. Jakarta: Rineka Cipta

Padila. 2014. Buku Ajar Keperawatan Maternitas. Yogyakarta: Nuha Medika.

Poliklinik Kesehatan Ibu dan Anak (KIA) Puskesmas Batu Kota Palu. 2018
Pongsibidang, Gabriellyn Sura; Abdullah, Zulkifli; Ansariadi. 2013. Faktor yang Berhubungan Dengan Keteraturan Kunjungan Antenatal di Wilayah Kerja Puskesmas Kapala Kitu Kabupaten Toraja Utara. Sulawesi Selatan : Universitas Hasanudin.I

Rukiyah,dkk. 2014. Asuahan Kebidanan I. Jakarta: TIM

Sunarti,2013. Asuhan Kehamilan: IN MEDIA

Survei Demografi Kesehatan Indonesia. 2012.

Yuninda Asih, Artikel ibu hamil, 2018. (online). (http://st298253.sitekno.com/article/8 55 78/kunjungan-ibu-hamil.html). Diambilpada tanggal 2 Februari 2018 